\title{
СОЦИАЛЬНОЕ САМОЧУВСТВИЕ МОЛОДЫХ РАБОТНИКОВ ПРОМЫШЛЕННЫХ ПРЕДПРИЯТИЙ: ИНДИКАТОРЫ И ФАКТОРЫ
}

\begin{abstract}
В статье рассматривается специфика индикаторов социального самочувствия, выделяемых исследователями в европейских и российских замерах. На основе сравнения понятий «социальное самочувствие» и «субъективное благополучие» выделяются общие для отечественных и зарубежных подходов индикаторы для их анализа: удовлетворенность жизнью в целом и уверенность в завтрашнем дне. Цель анализа - выявление факторов, определяющих социальное самочувствие. Прикладное значение такого знания - коррекция направлений социальной политики предприятий, которые влияют на самочувствие работников. Актуальность изменений связана с наблюдаемой на отечественных промышленных предприятиях устойчивой тенденции оттока кадров. В статье анализируется влияние на социальное самочувствие двух групп факторов: производственных (условия труда, заработная плата и т.д.) и внепроизводственных (жилищные условия). Важность этих факторов подтверждается с помощью корреляционного анализа данных массовых опросов среди молодых (до 30 лет) работников российских промышленных предприятий. Для такого анализа использованы данные социологических исследований, выполненных в режиме мониторинга по единой методологии в одном из российских регионов Поволжья в 2012-2014 гг. Для этой статьи с помощью программы SPSS из общих массивов ответов работников промышленности за 2012-2013 гг. были отобраны ответы молодых работников (2012 г. $-\mathrm{N}=242,2013$ г. $-\mathrm{N}=168$ ), а также взяты данные опроса 2014 г.
\end{abstract}

Владислав Юрьевич Бочаров - к.соц.н., доцент кафедры социологии и культурологии Самарского национального исследовательского университета, ассоциированный научный сотрудник СИ РАН, Санкт-Петербург, Россия. Электронная почта: vlad.bocharov@gmail.com

Юлия Владимировна Васькина -к.соц.н., доцент кафедры социологии и культурологии Самарского национального исследовательского университета, ассоциированный научный сотрудник СИ РАН, Санкт-Петербург, Россия. Электронная почта: vaskina18.05@gmail.com 
«молодых специалистов» (N=122). При опросе 2014 г. дополнительным критерием отбора респондентов (помимо возрастного) выступало среднее или высшее профессиональное образование по специальности или профессии, предполагающей трудоустройство в промышленности, поэтому они были названы в исследовании «молодые специалисты». Взаимосвязи между социальным самочувствием работников и разными факторами позволяют формировать менеджменту грамотную социальную политику на российских промышленных предприятиях. В представленной статье обосновывается необходимость гибкого подхода к выбору индикаторов социального самочувствия для различных социальных групп.

Ключевые слова: социальное самочувствие, удовлетворенность жизнью, мониторинг социально-трудовой сферы, молодые работники, промышленные предприятия

DOI: $10.17323 / 727-0634-2017-15-2-201-216$

Интерес к изучению социального самочувствия различных социальных групп в социологических исследованиях не ослабевает с конца 1980-х гг. Такой интерес, как правило, объясняется практическим значением анализа уровня социального самочувствия для разработки и реализации социальной политики, а также «адекватных мер социальной поддержки различных категорий населения» (Блохина, Григорьев 2015: 182). В отечественной социологии к настоящему времени существует несколько подходов к анализу термина «социальное самочувствие» и возможностей его измерения (Суняйкина 2011; Михайлова 2010; Крупец 2003).

Некоторые отечественные авторы подчеркивают, что с определенными допущениями можно говорить о корректном сравнении термина «социальное самочувствие» с зарубежным термином «subjective well-being» («субъективное благополучие»), что «позволяет не только проводить взаимодополняющую проблематизацию и выстраивать исследовательские параллели, но и заимствовать стратегии операционализации» (Рогозин 2007:97; также см.: Huppert 2014). Тем не менее такая позиция уязвима для критики, причем некоторые авторы вообще склонны считать отечественный термин «социальное самочувствие» не самым удачным (Петрова 2002: 51). Не разделяя крайних позиций, мы полагаем, что оба термина могут быть полезны исследователям, особенно учитывая возможности сравнения уровня социального самочувствия в нашей стране с уровнем других стран. Разумеется, при его измерении различные исследовательские группы разрабатывают авторские системы индикаторов, в большинстве которых есть индикатор «удовлетворенность жизнью» («life satisfaction»). Более того, этот показатель часто считается основным (Huppert 2014), что позволяет проводить межстрановые сравнения уровня социального самочувствия.

Понятие «subjective well-being» рассматривается как категория, включающая в себя три основных набора индикаторов: (1) эмоциональные 
реакции, (2) удовлетворенности различными сферами жизни и (3) суждения об удовлетворенности жизнью в целом. Выделяют шесть групп факторов, которые оказывают влияние на «subjective well-being»: личностные факторы; контекстные и ситуационные факторы; демографические факторы; институциональные факторы; факторы окружающей среды; экономические факторы (Hoorn 2007).

Отметим, что в общеевропейском проекте Евростата (статистическая служба ЕС) подробно анализируются несколько национальных методик измерения «subjective well-being» и предлагаются универсальные переменные для измерения его уровня. Для этого делается попытка сгруппировать субъективные показатели «subjective well-being» на основе иерархической теории Абрахама Маслоу и теории Ричарда Райана и Эдварда Деси (Deci, Ryan 2000), а объективные - на основе комбинации теории Таухидура Рахмана (Rahman et al. 2011) и «подхода возможностей», capabilities approach (Ootegem, Verhofstadt 2015). В результате аналитики Евростата сконструировали блоки субъективных и объективных характеристик, подлежащих измерению (табл. 1).

Таблииа 1.

Измеряемые компоненты «subjective well-being» (Eurostat 2010: 17)

\begin{tabular}{|c|c|}
\hline $\begin{array}{c}\text { Базисные (А. Маслоу) } \\
\text { и физиологические (Э. Деси и Р. Райан) } \\
\text { потребности }\end{array}$ & $\begin{array}{c}\text { T. Рахман } \\
\text { и «подход возможнностей» }\end{array}$ \\
\hline $\begin{array}{l}\text { Физиологические потребности } \\
\text { (пища, вода, здоровье, жилище; и финан- } \\
\text { совые средства для этого) }\end{array}$ & $\begin{array}{l}\text { Жизненные стандарты } \\
\text { Здоровье и долголетие } \\
\text { Основные права в сфере здоровья } \\
\text { и доходов }\end{array}$ \\
\hline $\begin{array}{l}\text { Безопасность/защита } \\
\text { (условия гарантии физиологических } \\
\text { потребностей в будущем): доверие, } \\
\text { образование, социальная защита, } \\
\text { гарантии занятости }\end{array}$ & $\begin{array}{l}\text { Безопасность } \\
\text { Образование } \\
\text { Физическая (окружающая) среда }\end{array}$ \\
\hline $\begin{array}{l}\text { Профессиональная деятельность/ } \\
\text { индивидуальная активность } \\
\text { (самореализация) + автономия/свобода } \\
\text { (включая время для этих видов } \\
\text { деятельности) }\end{array}$ & $\begin{array}{l}\text { Производительная и ценностно- } \\
\text { обусловленная активность }\end{array}$ \\
\hline $\begin{array}{l}\text { Признание (участие в отношениях/ } \\
\text { принадлежность) + осуществление } \\
\text { социальной/общественной активности } \\
\text { (индивидуальные взаимодействия и обще- } \\
\text { ственное участие) (включая время на эти } \\
\text { виды деятельности) }\end{array}$ & $\begin{array}{l}\text { Качество социальных взаимодействий } \\
\text { Основные права на социальном } \\
\text { и общественном уровне (дискриминация } \\
\text { и т.п.) }\end{array}$ \\
\hline Компетентность / самооценка & - \\
\hline
\end{tabular}


Российская действительность иная. В контексте отечественных исследований социальное самочувствие за редким исключением операционализируется с позиций удовлетворенности материально-бытовыми, производственными и общественно-политическими факторами. Стержневой фокус отечественного анализа социального самочувствия концентрируется на индикаторах, которые позволяют судить либо об уровне благополучия/ неблагополучия той или иной социальной группы, либо о степени успешности социальной адаптации к условиям своей жизни (Крупец 2003: 143). Так, к индикаторам социального самочувствия могут быть отнесены: удовлетворенность разными аспектами жизни; уверенность в завтрашним днем; наиболее беспокоящие проблемы; оценка социальной значимости экономических и политических реформ; степень готовности к новым испытаниям, связанным с продолжением реформ; отношение к деятельности властных структур; готовность лично участвовать в социально-политической жизни общества. При этом исследователями делается вывод, что «на протяжении последнего десятилетия большинство респондентов определяющим в своем социальном и психологическом самочувствии называют уровень экономического и материального благосостояния» (Егорова, Хасбулатова 2002:48).

Другая группа индикаторов социального самочувствия (наиболее близкая к понятию «subjective well-being») предлагается в работе Ольги Суняйкиной: (1) уровень жизни (доход; материальное положение, обеспеченность; занятость и безработица; гарантированность социальной защиты; качество свободного времени); (2) эмоционально-психологическое состояние; (3) социальные самоощущения: идентификация (состояние комфортности; социальные ценности); (4) жизненные и адаптационные стратегии; (5) самооценка потенциала (профессионального, социального опыта, личностных качеств) (Суняйкина 2011: 101). Ряд авторов говорят о факторах, которые влияют на социальное самочувствие. Например, ведущими факторами могут выступать: социально-производственная среда («сфера труда»); сфера социальной защиты, особенно значимая для неработающего населения, больных, инвалидов, человека, попавшего в трудную жизненную ситуацию; и жилищная сфера, «жилищные проблемы» (Михайлова 2010).

Это разнообразие подходов и наборов индикаторов объяснимо сложностью изучаемого феномена, поскольку в обобщенном показателе, как правило, требуется отразить уровень социального самочувствия населения страны или региона, состоящего из неоднородных по социально-демографическим и иным характеристикам социальных групп. Главной целью таких исследований, как правило, и является определение уровня социального самочувствия. Иную специфику имеют исследования социального самочувствия работников промышленных предприятий, в них определение уровня социального самочувствия в абсолютном большинстве случаев является одной из частных задач, в этой связи методика его измерения ограничивается небольшим списком индикаторов. 


\section{Социальное самочувствие работников предприятий: специфика измерения и эмпирическая база мониторинговых исследований}

Одно из первых исследований, выполненных на промышленных предприятиях с целью исследования социального самочувствия работников, проведено под руководством Аллы Русалиновой в 1991-1992 гг. Оно позволило обосновать основные показатели социального самочувствия работников промышленных предприятий. К числу таких показателей отнесли: (1) уровень удовлетворенности жизнью в целом; (2) уровень уверенности в завтрашнем дне (это два основных показателя, используемые в мировой практике для сравнительного анализа качества жизни населения разных стран); (3) оценку степени личного переживания чувства социального дискомфорта, т.е. неустроенности и неуютности в жизни; (4) качественную характеристику доминирующего эмоционально-динамического настроя личности, отражающего его стратегическую жизненную поведенческую установку; (5) показатель общей удовлетворенности работой в целом и ее отдельными характеристиками (Грачев, Русалинова 2007:9). Позднее был сделан вывод, что «влияние удовлетворенности работой на предприятии на удовлетворенность жизнью весьма слабое или его вообще нет», тогда как в первую очередь на удовлетворенность жизнью влияют факторы повседневной жизни: питание, одежда и жилищные условия (Бессокирная 2014: 185).

В наших мониторинговых исследованиях объектом анализа выступают наемные работники промышленных предприятий (Бочаров 2010). Исследования, которые выполняются НИИ социальных технологий Самарского университета на промышленных предприятиях, дают представление о многих аспектах сложившейся здесь социально-трудовой ситуации. Анализируется состояние различных показателей социально-трудовой сферы: трудовой потенциал работников, оплата труда и уровень жизни работников, уровень развития трудовых отношений на предприятиях, уровень социальной напряженности, деятельность профсоюзов, уровень мотивации персонала, перспективы становления социального партнерства на предприятиях и т.д. (Бочаров, Тукумцев 2015; Васькина 2015). В статье приводятся данные относительно динамики социального самочувствия молодых (до 30 лет) наемных работников. Используются данные массовых опросов мониторинга социально-трудовой сферы промышленности, проведенных НИИ социальных технологий Самарского университета по единой методологической программе в 2012-2014 гг. (выборка: квотно-целевая, ошибка выборки не превышает $5 \%$ ).

В 2012-2013 гг. исследования проводились на группе предприятий пяти видов экономической деятельности обрабатывающих производств. Социологический опрос был осуществлен на десяти предприятиях (каждый год), 
расположенных в трех городских округах Поволжского региона. Всего опрашивалось по 700 респондентов каждый год. Для нашего анализа с помощью программы SPSS из общих массивов ответов работников промышленности за 2012-2013 гг. были отобраны ответы молодых работников: 2012 г.-N=242, 2013 г. - N=168. Осенью 2014 г. исследование было проведено на шести предприятиях, относящихся к виду экономической деятельности «Производство судов, летательных и космических аппаратов и прочих транспортных средств» («аэрокосмический кластер»). В ходе исследования проведен анкетный опрос и интервьюирование 280 респондентов - молодых специалистов, обучающихся и экспертов - руководителей и специалистов предприятий и образовательных организаций. Для статьи отобраны ответы молодых специалистов предприятий, полученные в ходе массового анкетного опроса $(\mathrm{N}=122)$.

Главной целью исследования социального самочувствия молодых работников предприятий было выяснить, какие факторы его определяют. Очевидное прикладное управленческое значение такого знания - это коррекция направлений социальной политики предприятий (которая оказывает влияние на социальное самочувствие молодых работников). Ее актуальность связана с наблюдаемой на отечественных промышленных предприятиях долговременной устойчивой тенденцией оттока кадров. Распространена ситуация, когда молодежь, трудоустраивающаяся на промышленные предприятия, через некоторое время покидает их в поиске нового места работы. Так, согласно данным отделов кадров обследованных в рамках мониторинговых исследований промышленных предприятий НИИ социальных технологий в 2014 г., от 30 до 50\% молодых работников увольняются с предприятий в течение первого года работы (Авдошина 2015: 14). При этом соотношение уволившихся молодых работников составляет от 11,1\% до 387,5\% (это означает, что за год молодых специалистов уволилось с предприятия в 3,875 раза больше, чем трудоустроилось). Основными причинами увольнений являются увольнения по собственному желанию вследствие низкой заработной платы и по семейным обстоятельствам - из-за отсутствия жилья. В целом текучесть кадров среди молодых работников на обследованных в 2014 г. предприятиях варьировалась от 2,2\% до 54,1\%.

Основные индикаторы социального самочувствия молодых работников промышленных предприятий: «удовлетворенность жизнью» и «уверенность в завтрашнем дне».

\section{Удовлетворенность молодых работников жизнью в целом}

Большинство молодых работников (от 2/3 в 2012-2013 гг. до 4/5 - в 2014 г.) отвечали, что удовлетворены тем, как складывается их жизнь (в анкете использовался вопрос: «Удовлетворены ли Вы тем, как складывается жизнь?»). Соотношение долей удовлетворенных и неудовлетворенных жизнью молодых работников отражено в индексе удовлетворенности жизнью, который имеет 
устойчивое положительное значение (табл. 2). Все индексы удовлетворенности (жизнью, условиями труда, оплатой труда, жилищными условиями), представленные в этой статье имеют значение от +1 до -1. В качестве алгоритма расчета использована формула, приведенная в книге «Человек и его работа в СССР и после» (Здравомыслов, Ядов 2003: 76).

Таблица 2.

\section{Индекс удовлетворенности жизнью}

$\begin{array}{ll}\text { В среднем по массиву 2012 г. } & 0,39 \\ \text { В среднем по массиву 2013 г. } & 0,36 \\ \text { В среднем по массиву 2014 г. } & 0,53\end{array}$

Корреляционный анализ взаимосвязей таких факторов производственной ситуации как размер оплаты труда и условия труда, а также жилищные условия молодежи со степенью удовлетворенности жизнью, показал умеренную силу взаимосвязи (табл. 3). Выше мы писали, что далеко не во всех исследованиях присутствует взаимосвязь между удовлетворенностью жизнью и удовлетворенностью работой. Тем не менее сравнение степени удовлетворенности жизнью со степенью удовлетворенности работой выявляет во многом схожее распределение оценок, в том числе и по данным опроса 2014 г., когда корреляция связи не являлась значимой.

Таблийа 3.

Сила связи между уровнем удовлетворенности жизнью

и уровнем удовлетворенности отдельными элементами производственной и непроизводственной среды (значения коэффициента корреляции Кэнделла)

\begin{tabular}{llll}
\hline \multicolumn{1}{c}{ Аспекты трудовой деятельности } & $\mathbf{2 0 1 2}$ z. & $\mathbf{2 0 1 3}$ z. & $\mathbf{2 0 1 4}$ z. \\
\hline Удовлетворенность жилищными условиями & 0,263 & 0,358 & 0,184 \\
Удовлетворенность размером оплаты труда & 0,215 & 0,385 & 0,160 \\
Удовлетворенность условиями труда & 0,168 & 0,327 & 0,183 \\
Удовлетворенность работой в целом & 0,327 & 0,282 & 0,141 \\
\hline
\end{tabular}

Примечание: Для 2012-2013 гг.- все корреляции значимы на уровне 0.01 (двусторонняя). Для 2014 г.- цветом выделена не значимая корреляция, остальные корреляции - значимы на уровне 0.05 (двусторонняя).

В свою очередь, степень удовлетворенности жизнью связана с наличием или отсутствием желания у респондентов искать новую работу. Среди работников, удовлетворенных тем, как складывается жизнь, доля 
желающих сменить место работы заметно ниже (12,1\%), чем среди тех, кто жизнью не удовлетворен (30,7\%).

\section{Степень оптимизма в оценке молодыми работниками своего настоящего и будущего}

В исследованиях 2012-2014 гг. вопрос относительно оценок молодыми работниками характера ближайших перемен в жизни их семей был сформулирован следующим образом: «Как Bbl считаете, через год ваша семья будет жить лучше или хуже, чем сейчас?». По результатам опроса в исследованиях 2012-2013 гг. около 1/3 молодых работников оптимистично («жизнь станет значительно или несколько лучше») воспринимали возможные ближайшие изменения в жизни семей. В исследовании 2014 г. доля оптимистично настроенных молодых работников составила почти $60 \%$ (опрос проводился до того, как кризисные тенденции в экономике 2014 г. стали очевидны). Здесь необходимо учитывать специфику экономически стабильных и благополучных на фоне оборонного заказа предприятий «аэрокосмического кластера». Поэтому более позитивное (по сравнению с данными опросов в целом по обрабатывающим производствам) восприятие размера заработной платы и условий труда молодыми работниками аэрокосмического кластера не явилось для исследователей неожиданным.

\section{Характеристика основных факторов, влияющих на социальное самочувствие молодых работников}

\section{Производственные факторы: удовлетворенность оплатой и условиями труда}

Доли работников в той или иной мере удовлетворенных уровнем оплаты своего труда в 2012-2013 гг. составляли около 1/3 опрошенных. По результатам опроса 2014 г. доля удовлетворенных составила около половины опрошенных (51,7\%). Соотношение долей удовлетворенных и неудовлетворенных оплатой труда молодых работников отражено в индексе удовлетворенности зарплатой (табл. 4). По результатам исследований 2012-2013 гг. индекс удовлетворенности был отрицательным, а по результатам опроса 2014 г. достиг положительного значения. Тем не менее все индексы удовлетворенности молодых работников близки к нулевому значению, что свидетельствует о примерном равенстве долей удовлетворенных и не удовлетворенных своей зарплатой.

Отметим, что желаемый размер заработной платы молодых работников в 1,5 раза выше, чем реальный. Молодые работники называли примерно одинаковые размеры желаемой зарплаты, и они почти совпадали с данными статистики о средней зарплате, приводимыми для предприятий того вида экономической деятельности на которых происходил опрос. 
Следовательно, молодые работники не характеризуются завышенными материальными запросами, вопреки распространенному стереотипу. При этом в интервью респонденты рационально обосновывали свои пожелания относительно заработной платы. В 2014 г. они говорили, что начальная заработная плата должна быть около 25 тыс. руб., пока нет своей семьи, и родители помогают материально. Но через несколько лет заработок должен повышаться таким образом, чтобы обеспечивать семью, решать жилищную проблему.

Таблица 4.

\section{Индекс удовлетворенности зарплатой}

$\begin{array}{lr}\text { В среднем по массиву 2012 г. } & -0,07 \\ \text { В среднем по массиву 2013 г. } & -0,06 \\ \text { В среднем по массиву 2014 г. } & 0,05\end{array}$

Для современного работника, тем более молодого, впервые приходящего на предприятие, состояние условий труда, помещений, в которых работают люди, становятся немаловажным аргументом в пользу выбора места работы и специальности. Для уже работающих на предприятии степень удовлетворенности условиями труда становится важной составляющей их отношения к работе и вносит свой вклад в формирование стабильности или текучести кадров. Результаты опросов 2012-2014 гг. показывают позитивную динамику увеличения доли молодых работников, удовлетворенных условиями своего труда (2012 г.-52,9\%, 2013 г.-63,0\%, 2014 г.- 77,5\%). Соответственно, росло и значение индекса удовлетворенности условиями труда (табл. 5).

\section{Индекс удовлетворенности условиями труда

$\begin{array}{ll}\text { В среднем по массиву } 2012 \text { г. } & 0,26 \\ \text { В среднем по массиву } 2013 \text { г. } & 0,34 \\ \text { В среднем по массиву } 2014 \text { г. } & 0,53\end{array}$

Такая динамика объясняется тем, что на многих обследованных промышленных предприятиях в период 2012-2014 гг. происходила модернизация производственного оборудования и реконструкция производственных площадей. Исследователи были свидетелями того, как молодые операторы работают на новом оборудовании «в пиджаках», не соприкасаясь с изготовляемыми деталями и смазочными материалами: они задают программу и контролируют ее исполнение. Такие работники в большей мере удовлетворены условиями труда. Те же, кто работает 
на оборудовании старых образцов, сталкиваются с такими аспектами как необходимость постоянного подъема тяжестей, работой в грязных помещениях, с устранением постоянных поломок и аварийными ситуациями, и имеют противоположное мнение по поводу условий труда. Таких работников довольно много даже по данным опроса 2014 г. (каждый пятый опрошенный).

\section{Жилищные условия молодых работников предприятий как главный внепроизводственный фактор социального самочувствия}

Помимо рассмотренных факторов производственной среды, влияние на социальное самочувствие молодых работников оказывают жилищные условия. Отметим, что в зарубежных исследованиях также показана взаимосвязь между размером жилой площади («living space») и социальным самочувствием («subjective well-being»). Логическая связь такая: размер жилья влияет на удовлетворенность жилищными условиями, которые влияют на удовлетворенность жизнью, а та, в свою очередь, является важнейшим компонентом социального самочувствия, т.е. социальное самочувствие функция уровня удовлетворенности жилищными условиями. При этом уточняется, что взаимосвязь, главным образом, обнаруживается среди мужчин (Foye 2016). Отечественными исследователями отмечается, что наиболее актуален жилищный вопрос для людей до 36 лет. В то же время, покупка квартир оказывается недоступной именно для молодых семей, от которых государство при этом ожидает воспроизводства населения. Поэтому у 44,7\% жилищная проблема вызывает чувство подавленности, бесперспективности, злости и раздражения (Михайлова 2010:49).

По данным нашего опроса 2014 г. более 40\% молодых специалистов проживали совместно с родителями, другими родственниками или соседями (в ходе исследований 2012-2013 гг. этот аспект жилищных условий не выяснялся), т.е. не имели достаточного жизненного пространства для создания семьи и тем более планирования детей. При этом по типу жилья молодые работники преимущественно живут в отдельных квартирах (об этом сообщили от чуть более половины в 2013 г. до 2/3 в 2014 г.), либо снимают жилье (так в 2012-2014 гг. делал примерно каждый пятый). По данным опросов 2012-2013 гг. доли молодых работников удовлетворенных жилищными условиями составляли около половины опрошенных (2012 г.- 51,7\%, индекс удовлетворенности 0,21; 2013 г.- 47,8\%, индекс удовлетворенности 0,03). В тоже время по данным опроса 2014 г. доля удовлетворенных жилищными условиями составила около $2 / 3$ опрошенных $(66,9 \%$, индекс удовлетворенности 0,45$)$.

В исследовании 2014 г. в ходе интервью с экспертами, молодыми специалистами и при анализе текстов коллективных договоров было установлено, что лишь некоторые предприятия не имели возможности 
помочь работникам в решении жилищного вопроса, но и они готовили определенные меры помощи по улучшению жилищных условий. На большинстве этих предприятий аэрокосмического кластера на момент проведения исследования действовали следующие виды поддержки: (1) частичная оплата аренды жилья; (2) предоставление мест в общежитиях; (3) помощь в выплате процентов по ипотеке; (4) предоставление беспроцентных ссуд работникам.

В целом по обрабатывающим производствам по данным исследований 2012-2013 гг., далеко не все предприятия находились в благополучном финансовом положении, в связи с этим не всем предприятиям было под силу оказывать помощь в решении жилищной проблемы. Однако на всех обследованных в 2012-2013 гг. и в 2014 г. предприятиях менеджмент понимал, что решение жилищной проблемы позволяет привлечь молодые кадры. Многие респонденты в ходе взятых исследователями интервью неоднократно выражали мнение, что главным фактором при выборе предприятия как будущего места работы является зарплата, а вторым по значимости - предоставление жилья. Поэтому решить проблему привлечения молодых специалистов - рабочих, не решив проблемы создания необходимых перспектив обеспечения их нормальными жилищными условиями, в современных российских условиях нереально.

\section{Заключение}

Социальное самочувствие - это многогранный феномен, связанный с оценкой своего социального и материального положения, жизненных обстоятельств и дальнейших перспектив их изменения. Оно зависит от целого ряда факторов объективного и субъективного характера и влияет на поведение человека, в том числе, в трудовой сфере. В этой связи изучение социального самочувствия является необходимой частью социологических исследований социально-трудовой сферы, поскольку показывает зависимость социального самочувствия от факторов производственной среды, от социальной политики, проводимой предприятием, а также выявляет взаимосвязь между уровнем социального самочувствия и потенциальной текучестью кадров.

Следовательно, выявленные в исследованиях факторы социального самочувствия могут быть использованы руководителями производственных организаций для повышения уровня социального самочувствия работников и как следствие - для снижения текучести молодых кадров. Социальное самочувствие молодых работников промышленных предприятий является тем показателем, который отражает результат воздействия многих жизненных обстоятельств, но в первую очередь связанных с условиями труда, его оплатой, с жилищными условиями. Данные корреляционного анализа показывают, что не удовлетворены жизнью, в основном, те, кто не удовлетворен условиями и оплатой труда, жилищными условиями. 
Улучшение состояния социального самочувствия молодых работников промышленных предприятий является не самоцелью, а инструментом управления персоналом и в целом социальной политики на современных российских промышленных предприятиях. При этом в силах руководителей предприятий повлиять не только на «производственные» факторы, формирующие социальное самочувствие работников. Грамотная социальная политика предприятий, в которой проявляется социальная ответственность работодателей, способна улучшить условия быта и жизни молодых работников. Есть положительные примеры, когда предприятия предоставляют работникам возможности отдыха и оздоровления (по льготным ценам или бесплатно), помогают решать бытовые вопросы (доставка транспортом предприятия до работы и обратно, организация льготного питания), участвуют в улучшении жилищных условий работающих (предоставляют ссуды на приобретение жилья), создают программы помощи нуждающимся. Подобные меры способны улучшить наиболее незащищенные стороны жизни работников, повысить уровень их социального самочувствия и, в результате, избежать тех негативных последствий, которые связаны с его низким уровнем.

\section{Выражения благодарности}

Статья выполнена по результатам исследований, ведущихся по программе мониторинга социально-трудовой сферы НИИ социальных технологий Самарского университета. Авторы выражают глубокую признательность и благодарность коллегам по данному исследовательскому проекту: директору НИИ социальных технологий к.соц.н., доценту Н. В. Авдошиной и инициатору мониторинговых исследований, разработчику их методологии и своему учителю - к.ф.н., доценту Б. Г. Тукумцеву за сотрудничество, помощь в реализации исследований и творческое вдохновение.

\section{Список источников}

Авдошина Н.В. (2015) Молодые специалисты на современном производстве: проблемы адаптации. Экономика и социология, 25 (1): 13-17.

Бессокирная Г.П. (2014) Динамика социального самочувствия рабочих в трансформирующейся России. И. Е. Фадеева, В. А. Сулимов, Л. В. Гурленова (ред.) Питирим Сорокин и парадигмы глобального развития ХХІ века (к 125-летию со дня рождения), Сыктывкар: СыктГУ: 179-189.

Блохина М.В., Григорьев Л.Г. (2015) Социальное самочувствие тверских студентов: опыт социологического исследования. Власть, (10): 182-187.

Бочаров В. Ю., Тукумцев Б. Г. (2015) Социальное партнерство на промышленных предприятиях. И.И. Елисеева, Р.Г. Браславский, А.С. Быстрова, К. С. Дивиденко, Е.А. Иванова, М.В. Масловский, Д.Б. Тев, И. Шубрт (ред.) Петербургская соииология сегодня, СПб.: Нестор-История: 10-63. 
Бочаров В. Ю. (2010) Социальный институт наемного труда в современной России, Самара: Самарский университет.

Васькина Ю.В. (2015) Заработная плата и уровень жизни работников промышленности Поволжья. И.И. Елисеева, Р.Г. Браславский, А. С. Быстрова, К. С. Дивиденко, Е.А. Иванова, М.В. Масловский, Д. Б. Тев, И. Шубрт (ред.) Петербургская социология сегодня, СПб.: Нестор-История: 236-265.

Грачев А.А., Русалинова А.А. (2007) Социальное самочувствие человека в организации. Известия РГПИ им. А. И. Гериена, 8 (30): 7-17.

Егорова Л.С., Хасбулатова О.А. (2002) Социальное самочувствие женщин и мужчин в средних городах России. Социологические исследования, (11): 48-54.

Здравомыслов А.Г., Ядов В.А. (2003) Человек и его работа в СССР и после, М.: Аспект Пресс.

Крупец Я.Н. (2003) Социальное самочувствие как интегральный показатель адаптированности. Социологические исследования, (4): 143-144.

Михайлова Л.И. (2010) Социальное самочувствие и восприятие будущего россиянами. Сочиологические исследования, (3): 45-50.

Петрова Л.Е. (2002) Социальное самочувствие молодежи. Социологические исследования, (11):50-66.

Рогозин Д. (2007) Тестирование вопросов о социальном самочувствии. Социальная реальность, (2): 97-113.

Суняйкина О.Н. (2011) Понятие «социальное самочувствие» в социологии. Вестник Мордовского университета, (3): 98-101.

Deci E. L., Ryan R. M. (2000) The 'What' and 'Why' of Goal Pursuits: Human Needs and the Self-Determination of Behavior. Psychological Inquiry, 11 (4):227-268.

Eurostat (2010) Feasibility Study for Well-Being Indicators: Critical Review. Доступно по ссылке: https:/goo.gl/KHkgcs (дата обращения: 2 июля 2016).

Foye C. (2016) The Relationship Between Size of Living Space and Subjective Well-Being. Journal of Happiness Studies, March: 1-35.

Hoorn A. (2007) A Short Introduction to Subjective Well-Being: Its Measurement, Correlates and Policy Use. Доступно по ссылке: https:/goo.gl/crItIh (дата обращения: 2 июля 2016).

Huppert F. A. (2014) The State of Wellbeing Science: Concepts, Measures, Interventions, and Policies. F. A. Huppert, C. L. Cooper (eds.) Wellbeing: A Complete Reference Guide. Interventions and Policies to Enhance Wellbeing. Volume VI. Wiley Clinical Psychology Handbooks, Dublin: John Wiley and Sons Ltd: 1-50.

Ootegem L., Verhofstadt E. (2015) Perceived Capabilities as an Aggregated Indicator for Well-Being. Applied Research in Quality of Life, 10 (4): 615-629.

Rahman T., Mittelhammer R., Wandschneider P. (2011) Measuring Quality of Life Across Countries: A Multiple Indicators and Multiple Causes Approach. Journal of Behavioral and Experimental Economics, 40 (1): 43-52. 
Vladislav Bocharov, Julia Vaskina

\section{YOUNG WORKERS' FROM THE INDUSTRIAL ENTERPRISES SOCIAL WELL-BEING: INDICATORS AND FACTORS}

In this article we examine the specific features behind social well-being indicators, which have been previously outlined by European and Russian researchers. Based on a comparison of the concepts of 'social well-being' and 'subjective well-being', this article highlights two common indicators for future domestic and foreign studies: satisfaction with life in general and confidence in the future. The main purpose of this study was to find out what factors impact on the social well-being of young workers. The obvious value of such knowledge is the adjustment of the social policy directions in the workplace to match young workers expectations of social well-being. What makes such social policy adjustments relevant and important is their effectiveness in reducing the outflow of personnel that has been observable in Russian industrial enterprises over a long period. This article deals with the impact of two groups of factors on social well-being: manufacturing (working conditions, wages, etc.) and non-manufacturing (housing). The importance of these factors is confirmed with the correlated analysis of mass surveys data from young (under 30 years) workers of Russian industrial enterprises. This analysis employed data from sociological research carried out during monitoring (based on a unified methodology) of the Russian district of the Volga region in 2012-2014. With the help of the SPSS programme we collected the data from young workers $(2012 \mathrm{~N}=242,2013 \mathrm{~N}=168)$ to build general patterns of industrial workers' responses (for 2012-2013). We also took survey data from 2014 on 'young specialists' ( $\mathrm{N}=122)$. In 2014, an additional criterion for selecting respondents (besides age-related) was the requirement for workers to have secondary or higher professional education. This education must correspond to their future specialization or profession in industry. This is why these workers were called 'young specialists' in our research. The revealed correlations between the social well-being of workers and a variety of factors can assist management in organizing the right social policy in the Russian industrial enterprises. In general, this article highlights the need for a flexible approach to selecting social well-being indicators for different social groups.

Keywords: social well-being, life satisfaction, social and labour sphere monitoring research, young workers, industrial enterprises

DOI: $10.17323 / 727-0634-2017-15-2-201-216$

Vladislav Bocharov - Kandidat nauk (PhD) in Sociology, Associate Professor, the Chairman of Sociology and Cultural Studies at Sociological department, Samara National Research, associate research fellow of The Sociological Institute of the Russian Academy of Sciences, St. Petersburg, Russian Federation. Email: vlad.bocharov@gmail.com

Julia Vaskina - Kandidat nauk (PhD) in Sociology, Associate Professor, the Chairman of Sociology and Cultural Studies at Sociological department, Samara National Research University, associate research fellow of The Sociological Institute of the Russian Academy of Sciences, St.Petersburg, Russian Federation. Email: vaskina18.05@gmail.com 


\section{References}

Avdoshina N. V. (2015) Molodye spetsialisty na sovremennom proizvodstve: problem adaptatsii [Young Specialists in Modern Production Facilities: Problems of Adaptation]. Ekonomika i sotsiologiya [Economics and Sociology], 25 (1): 13-17.

Bessokirnaya G.P. (2014) Dinamika sotsial'nogo samochuvstviya rabochikh v transformiruyushcheysya Rossii [The Dynamics of Social Well-Being of Workers in a Transforming Russia]. I. E. Fadeeva, V. A. Sulimov, L. V. Gurlenova (eds.) Pitirim Sorokin i paradigmy global'nogo razvitiya XXI veka (k 125-letiyu so dnya rozhdeniya) [Pitirim Sorokin and Paradigms of Global Development in the Twenty-first Century (the 125th anniversary)], Syktyvkar: SyktGU: 179-189.

Blokhina M.V., Grigor'ev L.G. (2015) Sotsial'noe samochuvstvie tverskikh studentov: opyt sotsiologicheskogo issledovaniya [The Social Well-Being of Students in Tver: An Attempt Towards Sociological Research]. Vlast' [Power], (10): 182-187.

Bocharov V. Yu., Tukumtsev B. G. (2015) Sotsial'noe partnerstvo na promyshlennykh predpriyatiyakh [Social Partnership in Industrial Enterprises]. I. I. Eliseeva, R. G. Braslavskiy, A. S. Bystrova, K. S. Dividenko, E. A. Ivanova, M. V. Maslovskiy, D. B. Tev, I. Shubrt (eds.) Peterburgskaya sotsiologiya segodnya [Petersburg Sociology Today], St. Petersburg: Nestor-Istoriya: 10-63.

Bocharov V. Yu. (2010) Sotsial'nyy institut naemnogo truda v sovremennoy Rossii [The Social Institution of Wage Labour in Modern Russia], Samara: Samarskiy universitet.

Deci E. L., Ryan R. M. (2000) The 'What' and 'Why' of Goal Pursuits: Human Needs and the Self-determination of Behavior. Psychological Inquiry, 11 (4):227-268.

Egorova L. S., Khasbulatova O.A. (2002) Sotsial'noe samochuvstvie zhenshchin i muzhchin v srednikh gorodakh Rossii [The Social Well-Being of Women and Men in Secondary Cities in Russia]. Sotsiologicheskie issledovaniya [Social Research], (11):48-54.

Eurostat (2010) Feasibility Study for Well-Being Indicators: Critical review. Available at: https://goo.g1/KHkgcs (accessed 2 July 2016).

Foye C. (2016) The Relationship Between Size of Living Space and Subjective Well-Being. Journal of Happiness Studies, March: 1-35.

Grachev A. A., Rusalinova A. A. (2007) Sotsial'noe samochuvstvie cheloveka v organizatsii [The social 'well-being' of a person within an organization]. Izvestiya RGPI im. A.I. Gertsena [Izvestia: Herzen University Journal of Humanities and Science], 8 (30): 7-17.

Hoorn A. (2007) A Short Introduction to Subjective Well-Being: Its Measurement, Correlates and Policy Use. Available at: https://goo.gl/crItIh (accessed 02 July 2016).

Huppert F. A. (2014) The State of Wellbeing Science: Concepts, Measures, Interventions, and Policies. F. A. Huppert, C. L. Cooper (eds.) Wellbeing: A Complete Reference Guide. Interventions and Policies to Enhance Wellbeing. Volume VI. Wiley Clinical Psychology Handbooks, Dublin: John Wiley and Sons Ltd: 1-50.

KrupetsYa.N. (2003) Sotsial'noe samochuvstvie kak integral'nyy pokazatel' adaptirovannosti [Social Well-Being as an Integral Component of Adaptation]. Sotsiologicheskie issledovaniya [Social Research], (4): 143-144. 
Mikhaylova L.I. (2010) Sotsial'noe samochuvstvie i vospriyatie budushchego rossiyanami [Social Well-Being and Russians' Perception of the Future]. Sotsiologicheskie issledovaniya [Social Research], (3): 45-50.

Ootegem L., Verhofstadt E. (2015) Perceived Capabilities as an Aggregated Indicator for Well-Being. Applied Research in Quality of Life, 10 (4): 615-629.

Petrova L.E. (2002) Sotsial'noe samochuvstvie molodezhi [The Social Well-Being of Young People]. Sotsiologicheskie Issledovaniya [Social Research], (11):50-66.

Rahman T., Mittelhammer R., Wandschneider P. (2011) Measuring Quality of Life Across Countries: A Multiple Indicators and Multiple Causes Approach. Journal of Behavioral and Experimental Economics, 40 (1): 43-52.

Rogozin D. (2007) Testirovanie voprosov o sotsial'nom samochuvstvii [Test Questions about Social Well-Being]. Sotsial'naya real'nost' [Social Reality], (2): 97-113.

Sunyaykina O. N. (2011) Ponyatie 'sotsial'noe samochuvstvie' v sotsiologii [The Concept of 'Social Well-Being' in Sociology]. Vestnik Mordovskogo universiteta [Bulletin of the University of Mordovia], (3): 98-101.

Vas'kina Yu. V. (2015) Zarabotnaya plata i uroven' zhizni rabotnikov promyshlennosti Povolzh'ya [The Wages and Living Standards of Workers in Industry]. I. I. Eliseeva, R. G. Braslavskiy, A. S. Bystrova, K. S. Dividenko, E. A. Ivanova, M. V. Maslovskiy, D. B. Tev, I. Shubrt (eds.) Peterburgskaya sotsiologiya segodnya [Petersburg Sociology Today], St. Petersburg: Nestor-Istoriya:236-265.

Zdravomyslov A. G., Yadov V.A. (2003) Chelovek i ego rabota $v$ SSSR i posle [Man and His Work in the USSR and Afterwards], Moscow: Aspekt Press. 